\title{
Interação entre a Política Monetária e os Preços das Habitações: Evidências para o Caso Brasileiro*
}

\section{The Interaction between Monetary Policy and Housing Prices: Evidences for the Brazilian Case}

\author{
Cássio Nóbrega Besarria** \\ Wellington Charles Lacerda Nobrega*** \\ José Danilo Bezerra Galdino**** \\ Ewerton Felipe de Melo Araujo*****
}

\begin{abstract}
Resumo: Esta pesquisa tem o propósito de analisar o grau de interdependência entre os preços habitacionais e as decisões de política monetária no Brasil. Essa relação é analisada a partir do modelo SVAR com restrições de sinais, no período de 2001 a 2014. Os resultados mostram que a inflação, o consumo, o produto real da economia e os preços das habitações respondem negativamente ao choque monetário contracionista. Já o choque nos preços das habitações promove um efeito riqueza positivo, afetando positivamente o consumo e o PIB. Por outro lado, o aumento nos preços das habitações afeta negativamente a inflação nos três primeiros trimestres; logo após, o nível geral de preços da economia volta a subir, ficando acima do patamar inicial. Esse efeito sobre a inflação faz com que a taxa de juros acompanhe o comportamento descrito por esse indicador e responda inicialmente de forma negativa ao aumento nos preços das habitações, aumentando a partir do terceiro trimestre.
\end{abstract}

Palavras-chave: Política monetária. Mercado habitacional. SVAR.

Abstract: This research has the purpose to estimate the degree of interrelationship between housing prices and monetary policy decisions in Brazil. This relationship was obtained through a signal restricted SVAR model for quarterly data sample for the periods between 2001 and 2014. The results demonstrated that inflation, consumption, real GDP of the economy and housing prices responds negatively to a restrictive monetary shock. A shock in housing prices promoted a positive wealth effect, positively affecting consumption and GDP. In other hand, the increase in housing prices affected negatively inflation in the firsts three quarters, soon after, the economy's general price level rose again, getting above the initial level. This effect on inflation made the interest rate to follow the behavior described

\footnotetext{
* Agradecemos aos pertinentes comentários e sugestões dos pareceristas anônimos. Além desses, somos gratos aos debatedores do XLIII Encontro Nacional de Economia, Márcio Issao Nakane (FEA/USP) e André Modenesi (IE/UFRJ) e do IV Encontro Pernambucano de Economia, Marcelo Eduardo Alves da Silva (Pimes/UFPE). Erros ainda existentes são de responsabilidade dos autores.

** Doutor em Economia pela Universidade Federal de Pernambuco (UFPE). Professor do curso de Economia da Universidade Federal da Paraíba (UFPB). E-mail: cassiodanobrega@yahoo.com.br

*** Doutorando em Economia pela Universidade Federal da Paraíba (UFPB). E-mail: wellington_ charles@hotmail.com

**** Graduado em Economia pela Universidade Federal de Pernambuco (UFPE). E-mail: danilobg.92@gmail.com

***** Doutorando em Economia pela Universidade Federal de Pernambuco (UFPE). E-mail: ewertonn. felipe@hotmail.com
} 
by this indicator and initially responded negatively to a rising in housing prices, increasing from the third quarter.

Keywords: Monetary policy. Housing market. SVAR.

JEL Classification: C11; E52; G12.

\section{Introdução}

A história mostra que uma série de crises econômicas está associada à origem de bolhas nos preços dos ativos, sendo o caso da "bolha das tulipas", ocorrido na Holanda no século XVII, um dos primeiros casos desse tipo de crise financeira registrado na história econômica mundial. Outros exemplos, como as crises dos Mares do Sul (1720) e do Mississippi (1720), o aumento dos preços dos imóveis e ações no Japão, Finlândia, Noruega e Suécia, em 1989, e na Tailândia, Malásia, Indonésia e vários outros países asiáticos, em 1997, o mercado acionário de balcão nos Estados Unidos (2000) e a crise subprime (2007) também se caracterizaram por episódios de bolhas.

Baseado em experiências passadas e nas consequências trazidas por essas crises, o entendimento dos fatores que afetam o comportamento do mercado de ativos (ações e habitações) e a forma como os gestores de política econômica devem reagir ao crescimento nos preços desses ativos têm se tornado de grande importância para as instituições financeiras, investidores do setor e autoridades monetárias, visto que flutuações nos preços dos ativos estão frequentemente associadas a alterações no setor financeiro e na economia real.

O debate recente sobre essa temática está voltado para a análise da resposta da política monetária aos choques nos preços dos ativos, em específico, os preços das habitações. A argumentação adotada por autores dessa vertente é que, ao reagir ao aumento nos preços dos ativos, o Banco Central reduz os desalinhamentos econômicos causados por essas flutuações. ${ }^{1}$ Em outras palavras, Furlanetto (2011) destaca que a resposta estimada pelo Banco Central não refletiria uma tentativa de direcionar os preços dos ativos aos seus fundamentos, mas seria apenas uma resposta indireta ao impacto que os preços dos ativos têm sobre a demanda agregada, em particular sobre as decisões de consumo e investimento.

Em específico para os preços das ações, Bernanke e Gertler (2001) destacam que os principais efeitos do aumento nos preços desses ativos são: efeito riqueza sobre o consumo e melhora na qualidade dos balanços das empresas. Segundo esses, os balanços das empresas dependem mais dos valores de mercado dos seus ativos que dos valores fundamentais ou patrimoniais, além de o aumento desses

1 É importante salientar que não há consenso acerca da resposta ou não da autoridade monetária aos choques nos preços dos ativos. Dentre os autores contrários a essa resposta, destacam-se Bernanke e Gertler (1999, 2001), Vickers (1999), Kuttner (2011) e Borio e Lowe (2002), entre outros. 
preços afetar a posição financeira das empresas e, assim, as garantias em relação ao financiamento externo à empresa.

Ao se analisar o ativo habitação, também é possível identificar o mecanismo de transmissão do efeito riqueza sobre o consumo, no qual, como descrito por Besarria, Paes e Silva (2016), o aumento nos preços das habitações se traduz em ganhos na riqueza imobiliária dos agentes econômicos detentores desse ativo, incrementando o seu consumo. Outra consequência desse choque são as condições de financiamento das famílias: à medida que as habitações se valorizam, essa apreciação flexibiliza as restrições de colaterais ou garantias que ligam a capacidade de crédito das famílias com o valor de suas casas. Com isso, quanto maior a sensibilidade das decisões de consumo das famílias, motivada pela flexibilização das condições de financiamento, mais vulneráveis estarão a mudanças nos ciclos dos preços das habitações.

Além dessa discussão, existe outro ramo da literatura que está voltado para a análise da forma ou dos canais pelos quais os instrumentos monetários e fiscais podem afetar o mercado de ativos. Dentre os autores que procuram incorporar essa análise, destacam-se Jappelli e Pistaferri (2010), Akitoby e Stratmann (2008), Ardagna (2009), Silva, Besarria e Carvalho (2014), sendo que esta pesquisa deter-se-á nos instrumentos monetários.

Em específico para o caso brasileiro, Silva, Besarria e Carvalho (2014) mostram que um aumento na taxa de juros tem dois efeitos sobre os preços das habitações: inicialmente negativo, levando a uma redução nos preços, e depois positivo, com sua elevação. O primeiro efeito é facilmente explicável tendo em vista os impactos negativos sobre o PIB e o consumo das famílias de um choque monetário contracionista. Por outro lado, o segundo efeito passou a ser interpretado como algo a ser investigado, e os autores sugeriram um novo price puzzle da política monetária, só que agora relacionado aos preços das habitações.

Baseando-se nessa discussão, esta pesquisa tem o propósito de analisar a interdependência entre os choques de política monetária e os preços das habitações. Os artigos propostos por Mendonça, Medrano e Sachsida (2011), Silva, Besarria e Carvalho (2014) e Besarria, Paes e Silva (2016) levam em consideração apenas efeitos unilaterais, ou seja, ou os preços dos imóveis respondem aos choques da política monetária ou a política monetária responde às mudanças nos preços das habitações. Esta pesquisa se diferencia das demais por analisar a interdependência entre os choques de política monetária e os preços dos imóveis, como proposto por Bjørnland e Leitemo (2009).

Essa interação passou a ganhar destaque na economia brasileira a partir de 2009, quando, com o objetivo de reduzir o déficit habitacional, foi implantado na economia brasileira o programa habitacional conhecido como Minha Casa, Minha Vida, conforme instituído pela Lei $n^{\circ} 11.977$, de 7 de julho de 2009. Um conjunto 
de fatores associados a esse programa, tais como crédito subsidiado para a compra de imóvel residencial, oferta de habitação fixa no curto prazo e elevado custo de produção, tem promovido crescimento excessivo nos preços habitacionais e levantado questionamentos, tais como: qual o efeito macroeconômico do aumento nos preços das habitações? Como a política monetária afeta o comportamento desses ativos? Há uma bolha no mercado habitacional brasileiro?

Parte desses questionamentos será respondida a partir dos procedimentos de identificação agnóstica proposta por Uhlig (2005). Além disso, será realizada, como exercício adicional, a análise de robustez dos resultados obtidos a partir do modelo de vetor autorregressivo estrutural (SVAR) por meio de três procedimentos distintos, descritos com mais detalhes na seção que trata dos procedimentos metodológicos. O objetivo dessa análise é verificar se os resultados obtidos a partir da identificação agnóstica são mantidos quando é alterada a especificação do modelo.

Além desta introdução, este estudo apresenta mais cinco seções: a seção 2 apresenta uma revisão de literatura sobre a interdependência entre política monetária e preços das habitações; a seção 3 aborda os procedimentos metodológicos e a base de dados que ajudaram a compor esta pesquisa; a seção 4 discute os resultados da pesquisa; a seção 5 desenvolve a análise de robustez; e, por fim, a seção 6 traça as considerações finais deste estudo.

\section{Debate Teórico Acerca da Interdependência entre Política Monetária e Preços das Habitações}

A discussão acerca da interdependência entre a política monetária e os preços dos ativos não é recente, sendo encontrados no atual estágio da pesquisa diversos estudos voltados para essa temática, especialmente as habitações. Dentre os estudos internacionais que tratam desta temática, pode-se citar Filardo (2000), Giuliodori (2004), Goodhart e Hofmann (2008) e Tan e Chen (2013), entre outros.

As experiências de crises financeiras em um cenário macroeconômico considerado estável, vivenciadas pelo Reino Unido e Japão no decorrer das décadas de 1980 e 1990, caracterizadas por grande elevação nos preços das ações e habitações em um ambiente de inflação estável, demonstram que controle inflacionário não é sinônimo de estabilidade financeira. Em seu estudo, Filardo (2000) constata semelhanças entre o andamento da economia norte-americana e o comportamento observado no Reino Unido e no Japão pré-recessão.

Em virtude disso, Filardo (2000) busca avaliar empiricamente se os resultados macroeconômicos de uma economia podem ser melhorados caso a política monetária reaja à volatilidade nos preços das ações e habitações. Os resultados encontrados pelo autor sugerem que os preços das habitações possuem capacida- 
de preditiva sobre a inflação futura, enquanto os preços das ações não a possuem. Além disso, foi possível verificar menor variabilidade no produto e inflação na medida em que a política monetária reage à volatilidade no preço dos ativos financeiros; contudo, o benefício dependerá diretamente da capacidade de o preço do ativo em questão antecipar a inflação esperada.

Em discussão subsequente, Giuliodori (2004) investiga as relações entre os choques de política monetária e os preços das habitações para nove países da Europa, com foco especial nos mecanismos de transmissão da política monetária associados aos preços no mercado imobiliário. Os resultados obtidos sugerem que um choque na taxa de juros afeta negativamente a dinâmica dos preços habitacionais e produto no curto prazo. Na vasta maioria dos países analisados, o choque na taxa de juros resulta na elevação dos custos da hipoteca, por meio do aumento da taxa de juros do refinanciamento imobiliário.

Em relação ao impacto dos preços habitacionais sobre o consumo das famílias, Giuliodori (2004) verifica que os preços das habitações possuem papel importante na transmissão da política monetária via consumo nos países em que o sistema de financiamento de habitações foi influenciado pelas reformas financeiras ocorridas na década de 1980.

Já Goodhart e Hofmann (2008) analisam as relações entre a oferta monetária, crédito, preço das habitações e atividade econômica para um conjunto de 17 países industrializados situados na Europa durante o período entre 1973 e 2006. Para isso, os autores utilizam um painel VAR com efeitos fixos para dados de periodicidade trimestral. Os resultados empíricos desse artigo apontam para a existência de uma relação multidirecional entre crédito, preço dos imóveis e estoque monetário. Especificamente, as variáveis monetárias possuem efeito significativo sobre o preço futuro dos imóveis, ao mesmo tempo que os preços dos imóveis possuem efeito significante no crescimento da oferta monetária e do crédito.

Segundo Goodhart e Hofmann (2008), os preços das habitações influenciam a demanda por crédito através do efeito riqueza sobre o consumo e o efeito $Q$ de Tobin sobre o investimento, proporcionando a causalidade entre os preços dos imóveis e o crédito. Posteriormente, os autores restringem o período analisado para 1985 a $2006 .{ }^{2}$ Nesse período mais curto, os resultados sugerem que os efeitos das variáveis monetárias se tornam mais fracos, enquanto os efeitos dos preços das habitações se tornam mais significantes. Especificamente, o impulso-resposta mostra que um choque nos preços das habitações tornou seus efeitos sobre o produto, taxa de juros e variáveis monetárias maiores em relação à estimação anterior, que considerou o período de 1973 a 2006.

2 Os autores justificam esse corte temporal no intuito de avaliar os efeitos da maior oferta de crédito em razão da liberalização e desregulamentação do sistema financeiro a partir de 1985. 
Já Tan e Chen (2013) investigam as relações entre os preços habitacionais e a política monetária na China, entre 1997 e 2012, utilizando a metodologia SVAR proposta por Bjørnland e Jacobsen (2012). A importância do mercado habitacional na economia chinesa é evidenciada pela apreciação de 130\% ocorrida durante o período analisado. Além disso, as habitações fazem parte de $70 \%$ da carteira dos agentes econômicos inseridos no meio urbano. Os autores utilizam como proxy para a política monetária a oferta monetária (M2) e a taxa de juros. ${ }^{3}$ Os resultados empíricos mostram que, para o caso chinês, um choque nos preços habitacionais possui grande efeito sobre o produto e a inflação, influenciando, também, a determinação da política monetária. Por outro lado, Tan e Chen (2013) identificam um price puzzle entre a taxa de juros e os preços habitacionais, tendo a oferta monetária maior impacto sobre a economia como instrumento de política monetária.

Direcionando a análise para a economia brasileira, Silva, Besarria e Carvalho (2014) e Besarria, Paes e Silva (2016) encontram evidências de que as relações entre os preços das habitações e a política monetária são significativas. Silva, Besarria e Carvalho (2014) analisam os impactos de choques na política monetária e $\square \mathrm{scal}$ sobre os preços das habitações no Brasil, através de uma abordagem SVAR. Os resultados empíricos sugerem que um choque na taxa de juros afeta os preços das habitações inicialmente de forma negativa, apresentando reversão nos períodos subsequentes. Por outro lado, o choque no gasto público afetou de forma positiva e persistente o consumo das famílias e os preços das habitações.

Por outro lado, Besarria, Paes e Silva (2016) analisam os efeitos de uma bolha nos preços dos ativos sobre as variáveis macroeconômicas. Esses autores observaram que os efeitos de uma bolha no mercado imobiliário estão relacionados a movimentos subsequentes no produto e inflação, em conformidade aos resultados encontrados por Goodhart e Hofmann (2008).

A discussão desses estudos mostra a importância que o comportamento dos preços dos imóveis passou a ter após a crise subprime. Esse novo papel dos preços das habitações nas decisões de política monetária não foi a única herança trazida por essa crise. Outros canais de transmissão da política monetária, pouco tratados até então, passaram a ganhar maior importância. Um desses, apesar do mecanismo não ser tratado neste estudo, foi o explorado no estudo de Borio e Zhu (2012), no qual discutem as implicações do canal de tomada de risco (risk-taking channel). A essência desse canal de transmissão está relacionada aos impactos da política monetária sobre o risco, dado que a política de juros afeta diretamente a percepção e o apreçamento do risco dos agentes econômicos. Os autores argumentam que as mudanças ocorridas no sistema financeiro nas últimas décadas, no que diz respeito a maior desregulamentação do capital financeiro, podem ter ampliado a importância do canal de tomada de risco.

3 As taxas de juros são controladas pelo governo chinês, não podendo flutuar livremente. 


\section{Procedimentos Metodológicos}

A discussão empírica adotada nesta pesquisa é baseada nos procedimentos de identificação agnóstica proposta por Uhlig (2005) e também utilizada por Besarria, Paes e Silva (2016). Inicialmente, assume-se $Z_{t}=\left[y_{t}, \pi_{t}, c_{t}, p h_{t}, i_{t}\right]$ ' como um vetor $(5 \times 1)$ de variáveis macroeconômicas, em quey $y_{t}$ e o PIB real, $\pi_{t}$ representa a taxa de inflação, $c_{t}$ é o índice de consumo das famílias, $p_{t}$ é o preço real das habitações e $\mathrm{i}_{\mathrm{t}}$ é a taxa de juros. O modelo VAR na forma estrutural pode ser representado por:

$$
A Z_{t}=\sum_{i=1}^{p} A_{i} Z_{t-1}+\varepsilon_{t} \text {, para } t=0: T
$$

Assumindo que A é não singular, então expressão 1, na sua forma reduzida, pode ser representada por:

$$
Z_{t}=\sum_{i=1}^{p} B_{i} Z_{t-1}+u_{t}
$$

em que $B_{i}=A_{i} A^{-1}$ para $i=1,2, \ldots, p, u_{t}=\varepsilon_{t} A^{-1}$.

Neste artigo o modelo VAR na sua forma reduzida é estimado para os dados da economia brasileira, utilizando a estratégia de identificação de restrição de sinais proposta por Uhlig (2005) e Silva, Besarria e Carvalho (2014), sendo este último aplicado para o caso brasileiro. A estimação do modelo VAR foi realizada de forma que as séries de preços de imóveis e instrumentos de política monetária foram ordenadas por último na estimação desse modelo, ficando dispostos por ordem de exogeneidade (incorporados na ordem que obedece à condição de termos mais exógenos para termos mais endógenos).

Em relação às restrições de sinais, destaca-se que, diferentemente da discussão proposta por Uhlig (2005), esta pesquisa se concentra no exercício de identificação dos efeitos de um choque contracionista na política monetária e um choque positivo nos preços das habitações brasileiras.

Quanto ao choque de política monetária, foram adotadas restrições nas quais a resposta do PIB e da taxa de inflação a um choque contracionista na taxa de juros é não positiva, como proposto por Uhlig (2005). Esse resultado também foi válido para a economia brasileira e apresentado por Silva, Besarria e Carvalho (2014), que estimaram um modelo Dinâmico Estocástico de Equilíbrio Geral (DSGE) para o Brasil e verificaram que um choque monetário contracionista gera efeitos negativos no produto e na inflação dessa economia. Assim, esse resultado foi utilizado como referência na imposição das restrições de sinais. Por outro lado, o choque nos preços das habitações não foi acompanhado por restrições de sinais, sendo observado o comportamento das demais variáveis, como pode ser visto na Tabela 1. 
Tabela 1 - Restrições de sinais impostas nas respostas estruturais

\begin{tabular}{c|c|c}
\hline Variável & Choque monetário & $\begin{array}{c}\text { Choque nos preços } \\
\text { habitacionais }\end{array}$ \\
\hline PIB & - & $?$ \\
\hline Inflação & - & $?$ \\
\hline Consumo & $?$ & $?$ \\
\hline Taxa de juros & + & $?$ \\
\hline Preço das habitações & $?$ & + \\
\hline
\end{tabular}

Fonte: Elaboração própria.

Nota: "+" indica resposta positiva no horizonte de restrição; "-" indica negativa; "?" indica irrestrito.

Dessa forma, o método consiste em mostrar que a matriz de relação contemporânea $\mathrm{A}$ em na equação 1 , tal que $\hat{\Sigma}=\mathrm{AA}$, pode ser definida por $\mathrm{A}=\tilde{\mathrm{A}} \mathrm{Q}$, sendo $Q$ uma matriz ortogonal [QQ' =I] e Ã é a decomposição de Cholesky da matriz estimada de variância dos resíduos $\widehat{\Sigma}$. Esse fato nos leva à identificação de uma única coluna $a$ da matriz A na equação 1 . Com isso, o problema se limita à determinação de um vetor $a$, associado ao vetor $m$-dimensional $\alpha$ de comprimento unitário, de modo que:

$$
a=\widetilde{A} \alpha
$$

Como já foi descrito, $a$ é uma coluna de A denominada por Uhlig (2005) de vetor impulso que contém as respostas contemporâneas das variáveis endógenas a um determinado choque, e $a$ é vetor coluna de $Q$ referente à posição correspondente. Como descrito por Uhlig (2005), dado o vetor impulso, é possível calcular a resposta ao impulso apropriado admitindo que $r_{i}(k)$ seja o impulso-resposta no período k do i-ésimo choque obtido da decomposição de Cholesky. O impulso-resposta para k períodos é representado por:

$$
\mathrm{r}_{\mathrm{a}}(\mathrm{k})=\sum_{\mathrm{i}=1}^{\mathrm{m}} \alpha_{\mathrm{i}} \mathrm{r}_{\mathrm{i}}(\mathrm{k})
$$

A expressão 4 mostra que é possível identificar o vetor de impulso correspondente aos choques de política monetária e nos preços dos ativos.

Além da discussão apresentada acima, será realizada a análise de robustez a partir de três métodos distintos: a) alteração das restrições impostas nas respostas estruturais para seis e oito trimestres; b) substituição das variáveis do PIB e Selic pelo PIB da construção civil e pela taxa de juros de longo prazo (TJLP); c) adoção de especificação alternativa para o SVAR com restrições de sinais por meio do 
método de estimação com restrições de curto e longo prazo proposto por Bjørnland e Jacobsen (2013). Esta pesquisa adaptará a discussão desenvolvida por esses autores para as características da economia brasileira, especificamente do setor imobiliário. Para mais detalhes sobre os procedimentos metodológicos propostos por Bjørnland e Leitemo (2009) e Bjørnland e Jacobsen (2013), ver o Apêndice E deste trabalho.

\subsection{Base de Dados}

A base de dados utilizada nesta pesquisa é composta por observações trimestrais do PIB, taxa Selic, índice nacional de preços ao consumidor amplo (IPCA), consumo e preços habitacionais, no período que compreende do segundo trimestre de 2001 ao segundo trimestre de 2014. A escolha do período de análise está relacionada à disponibilidade de dados, em específico do setor habitacional. A Tabela 2 descreve as variáveis utilizadas nesta pesquisa e suas respectivas fontes.

Tabela 2 - Descrição dos dados

\begin{tabular}{c|l|c|c}
\hline Variável & \multicolumn{1}{|c|}{ Descrição } & Fonte & Código \\
\hline PIB & PIB - preços básicos - índice - ref. 2001. & IBGE & 22097 \\
\hline Inflação & Inflação - IPCA - (\% a.a.) - ref. 2001. & IBGE & 13522 \\
\hline Consumo & $\begin{array}{l}\text { Consumo final das famílias - índice } \\
\text { encadeado - ref. 2001. }\end{array}$ & IBGE & 22100 \\
\hline $\begin{array}{c}\text { Preço } \\
\text { habitação }\end{array}$ & $\begin{array}{l}\text { Índice de preços reais dos imóveis } \\
\text { residenciais - ref. 2001. }\end{array}$ & BIS & BR:R:628 \\
\hline Taxa de juros & $\begin{array}{l}\text { Taxamédia ajustada dosfinanciamentos } \\
\text { diários apurados no Sistema Especial } \\
\text { de Liquidação e de Custódia (Selic) } \\
\text { para títulos federais. }\end{array}$ & BCB & 4189 \\
\hline
\end{tabular}

Fonte: Elaboração própria.

Destaca-se que a atividade econômica foi representada pelo índice do PIB, gerado a partir da série de PIB a preços básicos, em reais (milhões). Quanto à série de preço de venda dos imóveis, foi coletada no Bank for International Settlements (BIS) e representa os preços dos imóveis das regiões metropolitanas, com abrangência nacional. Em relação ao tratamento inicial dessas séries, ressalta-se que foi realizado o ajuste sazonal por meio do método X11-Arima. 


\section{Discussão dos Resultados}

A discussão da relação entre os choques de política monetária e os preços das habitações parte da análise do comportamento ao longo do tempo das séries da taxa de juros e dos preços dos ativos habitacionais. O Gráfico 1 apresenta um primeiro indicador da relação existente entre essas variáveis, e, como pode ser observado, há indícios de uma relação negativa entre esses termos, na qual elevações na taxa de juros são seguidas por redução nos preços das habitações. É importante ressaltar que as séries de juros e preços das habitações, descritas no Gráfico 1, foram tratadas a partir da eliminação das suas respectivas tendências.

Gráfico 1 - Relação entre a taxa de juros (Selic) e os preços das habitações

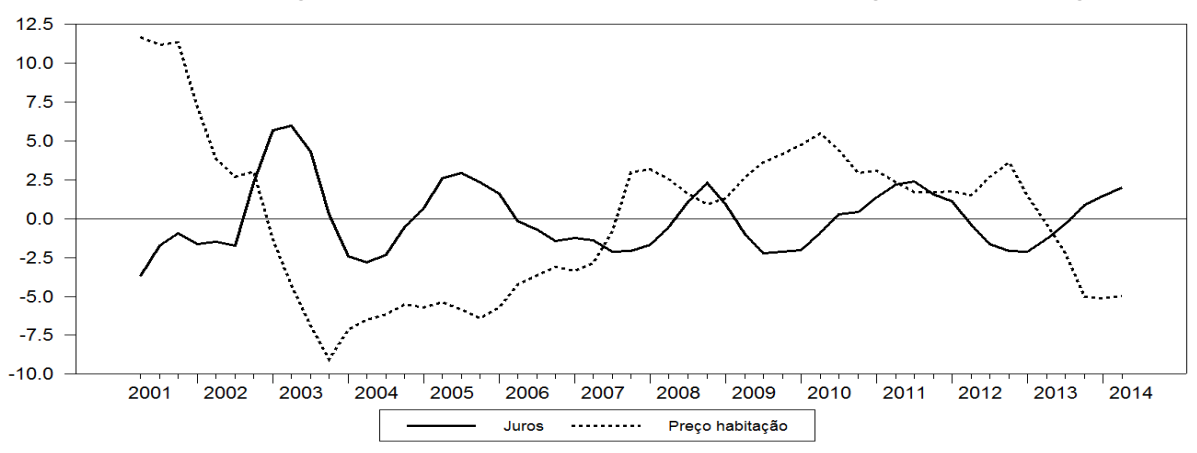

Fonte: Elaboração própria.

A estimação do coeficiente de correlação de Pearson fornece uma primeira evidência empírica dessa relação, com valor de -0.36, indicando a existência de correlação negativa (evidenciada pelo sinal do coeficiente) de fraca intensidade entre as variáveis. Apesar de ser um indicador simples, esse resultado se assemelha aos observados por Giuliodori (2004), Silva, Besarria e Carvalho (2014) e Besarria, Paes e Silva (2016), nos quais estes autores encontram evidências empíricas da existência de uma relação negativa entre os preços das habitações e a taxa de juros.

Quanto ao tratamento dos dados, foram realizados os testes de estacionariedade propostos por Dickey-Fuller, Kwiatkowski-Phillips-Schmidt-Shin (KPSS) e Phillips-Perron, com o propósito de verificar a ordem de integração das séries. Sabe-se que, por construção, os testes de Dickey-Fuller e KPSS possuem hipóteses de identificação de estacionariedade das séries opostas, sendo o primeiro com hipótese nula a não estacionariedade das séries e o segundo com estacionariedade. Ao confrontar os resultados obtidos a partir desses critérios de análise, foi possível verificar que algumas séries apresentaram conclusões conflituosas, como verificado para a taxa de juros que foi não estacionária no teste de Dickey-Fuller e estacio- 
nária no teste de KPSS. Para se alcançar um resultado mais confiável, foi aplicado um terceiro teste, conhecido como Phillips-Perron, que tem como hipótese nula a não estacionariedade das séries. Assim, foi possível verificar que as séries são não estacionárias em nível, porém, estáveis em diferença.

Tabela 3 - Testes de estacionariedade

\begin{tabular}{l|cccccc}
\hline \multirow{2}{*}{ Variável } & \multicolumn{3}{c}{ Dickey-Fuller } & \multicolumn{2}{c}{ KPSS } & \multicolumn{2}{c}{ Phillips-Perron } \\
\cline { 2 - 7 } & $\mathrm{t}_{\alpha}$ & $\mathrm{t}_{\text {crítico }}$ & $\hat{\eta}_{\mu}$ & $\eta_{\mu}$ & $\mathrm{t}_{\alpha}$ & $\mathrm{t}_{\text {crítico }}$ \\
\hline Consumo & -2.48 & -2.91 & 0.147 & 0.146 & -2.25 & -3.49 \\
PIB & -2.47 & -2.91 & 0.147 & 0.146 & -2.26 & -3.49 \\
Taxa de juros & -1.76 & -2.92 & 0.114 & 0.146 & -2.86 & -3.49 \\
Preço imóvel & -0.33 & -2.92 & 0.143 & 0.146 & -3.94 & -4.13 \\
Inflação & -3.00 & -3.58 & 0.16 & 0.146 & -3.44 & -3.49 \\
\hline
\end{tabular}

Fonte: Elaboração própria.

A discussão subsequente foi direcionada para a análise de uma possível relação de cointegração entre as séries tratadas. Para esse fim, foram utilizados os testes de cointegração propostos por Engle-Granger, Johansen e Phillips-Ouliaris. Os resultados dessa análise são apresentados na Tabela 6 do Apêndice A.

A análise de cointegração mostrou que as séries tratadas não compartilham de uma relação de equilíbrio de longo prazo. Devido a isso, a discussão limitar-se-á aos resultados obtidos a partir do modelo SVAR com restrições de sinais. Além disso, é importante ressaltar que o processo de estacionariedade das séries que será adotado neste artigo é o de eliminação da tendência das variáveis.

\subsection{Decomposição de Cholesky}

Segundo Bjørnland e Leitemo (2009), existindo forte simultaneidade entre os preços habitacionais e o choque de política monetária, espera-se que a decomposição de Cholesky não capte essa correlação, devido ao fato que um desses choques está restrito e não possui efeito imediato sobre as demais variáveis. O Gráfico 2 apresenta a simulação dos choques de política monetária e nos preços habitacionais, obtidos a partir da decomposição de Cholesky. 
Gráfico 2 - Impulso resposta com dois esquemas de identificação de Cholesky
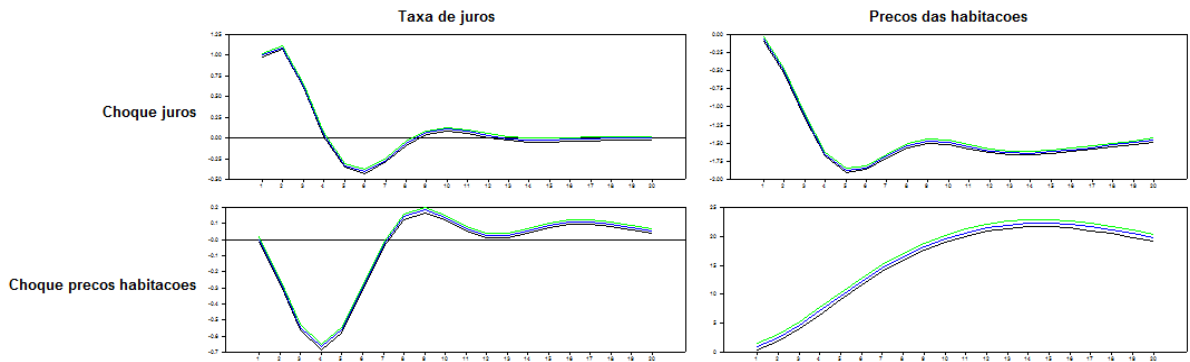

Fonte: Elaboração própria.

Nota: As bandas superior e inferior representam os intervalos de confiança ao nível de significância de 5\%. Modelo VAR estimado com constante e duas defasagens para o período amostral de 2001Q1 a 2014Q2, a identificação dos choques foi realizada através da decomposição de Cholesky (Ordenamento: PIB, inflação, consumo das famílias, preços das habitações e taxa de juros).

Pode-se observar, no Gráfico 2, que o efeito do choque contracionista na política monetária (elevação dos juros) conduz a uma redução contemporânea nos preços das habitações. Esses resultados se assemelham aos encontrados por Giuliodori (2004) e Besarria, Paes e Silva (2016), nos quais a elevação dos juros possui efeito negativo sobre a dinâmica dos preços das habitações como resultado do aumento do custo do financiamento habitacional, o qual reflete negativamente sobre a demanda e, em última instância, sobre os preços habitacionais.

Quanto à relação entre a taxa Selic e o custo do financiamento habitacional no Brasil, vale ressaltar, conforme destacado por Mendonça (2013), que a taxa de financiamento do imóvel não deveria ser representada pela taxa Selic, mas sim pela taxa realmente contratada, sendo que tal taxa seria derivada da interação entre a demanda e a oferta de financiamento habitacional. No entanto, no que se refere ao sistema financeiro de habitação ( $\mathrm{SFH}$ ), o governo fixa ou limita a taxa de financiamento ofertando recursos para concessão de empréstimos de modo a atender à demanda. Assim, a taxa de financiamento não obedece à lei da oferta $\mathrm{e}$ da procura. O governo determina a taxa e o volume de financiamento decorrente dela. Portanto, a identificação ocorre no sentido que o preço (taxa de financiamento) afeta a demanda, mas não o contrário. A curva de oferta é totalmente elástica.

Uma das consequências do direcionamento do crédito em tal proporção é que não existe ou, pelo menos, é muito diminuída a questão da causalidade reversa no processo de interação entre a oferta e a demanda por empréstimos habitacionais. Dadas essas características da economia brasileira e o fato de a rentabilidade dos fundos de renda fixa e dos Certificados de Depósitos Bancários (CDBs) 
ser altamente correlacionado com essa taxa, deriva-se a explicação do uso da taxa Selic como mecanismo de ajuste do custo do financiamento no Brasil.

Por outro lado, o choque nos preços das habitações resulta em uma redução imediata na taxa de juros, apresentando reversão do quadro no terceiro período após o choque, nos períodos subsequentes. À medida que os efeitos do choque se dissipam, a taxa de juros converge a seu nível inicial.

O canal de transmissão entre os choques nos preços dos ativos e a taxa de juros precisa ser investigado com mais detalhes. A literatura argumenta que o aumento nos preços das habitações pode afetar o patrimônio dos agentes detentores desse ativo e, com isso, promover um efeito riqueza. O aumento da riqueza das famílias afeta o consumo e o PIB da economia, sendo o efeito sobre a inflação uma incógnita a ser investigada. No caso brasileiro, por exemplo, com a adoção do regime de metas de inflação, a taxa de juros passou a ser utilizada para responder ao comportamento da inflação. Adaptando esse fato ao caso investigado nesta pesquisa, percebe-se que a resposta da taxa de juros ao aumento nos preços das habitações pode refletir apenas o efeito indireto desse choque na inflação. Dessa forma, além do efeito riqueza que pode surgir, procura-se verificar os efeitos do crescimento nos preços das habitações na inflação.

Quanto aos resultados obtidos a partir da decomposição de Cholesky, destaca-se que, apesar de apresentar resultados esperados e intuitivos, essa análise pode ser criticada pelo fato de restringir a simultaneidade dos choques, ou seja, por não captar os efeitos imediatos nos preços das habitações e na taxa de juros dos choques de política monetária e preços das habitações. No caso tratado neste artigo, é esperado que tanto a política monetária, quanto os preços das habitações venham a reagir a choques nesses termos, sendo que a restrição imposta pela ordenação de Cholesky não é capaz de captar essa interação.

\subsection{Resultados dos Choques}

Esta seção tem o propósito de apresentar a simultaneidade dos efeitos dos choques monetários e nos preços das habitações, obtidos por meio do modelo SVAR com identificação agnóstica, proposto por Uhlig (2005). O exercício que será apresentado no Gráfico 3 representa as funções impulsos-respostas obtidas a partir do choque monetário. Serão analisados os efeitos do aumento da taxa de juros no comportamento das séries dos preços das habitações, inflação, consumo e PIB. É importante destacar que foram impostas restrições de sinais de não positividade na resposta do PIB e da inflação por quatro trimestres, sendo observado o comportamento das demais variáveis. 
Gráfico 3 - Efeito do choque contracionista de política monetária no PIB, consumo, inflação e preços das habitações
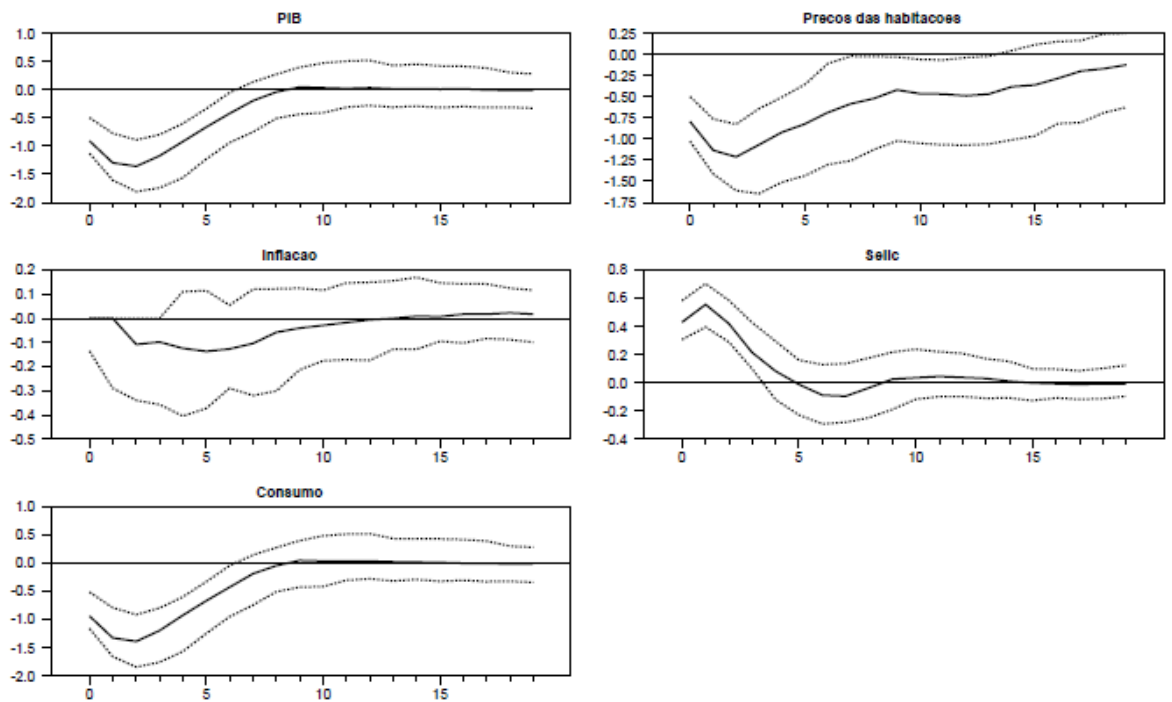

Fonte: Elaboração própria.

Nota: As linhas pontilhadas representam as bandas de probabilidade entre 0.16 e 0.84 , com horizonte de tempo de 20 trimestres e restrição de sinal pura para três trimestres, sendo eliminadas subsequentemente.

De modo geral, os resultados obtidos a partir do choque monetário contracionista mostraram que a inflação, o consumo e o produto real da economia responderam negativamente ao choque e a mediana da resposta dessas variáveis foi negativa por aproximadamente sete trimestres. O aumento de $0,5 \%$ na taxa de juros promoveu uma redução contemporânea de $1 \%$ no produto, $1 \%$ no consumo e $0,1 \%$ na inflação. Os resultados se assemelham aos encontrados por Peersman e Smets (2001).

Direcionando a análise para a variável de interesse, percebe-se que o aumento na taxa de juros promoveu uma redução contemporânea de $0,75 \%$ nos preços das habitações e, além disso, ocasionou efeitos negativos e persistentes sobre eles. Autores como Mendonça e Sachsida (2012) explicam que o mecanismo de transmissão desse choque para os preços habitacionais se dá pelo fato de grande parte das transações realizadas no mercado habitacional brasileiro ser de longa duração e indexada à taxa de juros de longo prazo. Dessa forma, o aumento da taxa de juros, referência da economia (Selic), promove aumento no custo do financiamento, redução nas transações imobiliárias e queda nos preços dos imóveis.

Ao se comparar os resultados obtidos nesta pesquisa com outros achados na literatura nacional, percebe-se que se assemelham aos encontrados por Men- 
donça, Medrano e Sachsida (2011). Esses autores, por meio de uma abordagem agnóstica com restrição de sinal pura, verificam que um impulso monetário contracionista afeta negativamente os preços das habitações.

É importante ressaltar que esses autores não tratam diretamente dos efeitos da política monetária sobre os preços das habitações, em que utilizaram o estoque de crédito de financiamento imobiliário como proxy do índice de preço dos imóveis. ${ }^{4}$ Dessa forma, o crédito imobiliário registrou uma redução contemporânea ao choque de $2 \%$. A intuição acerca desse fato é que, embora a poupança provavelmente cresça devido ao aumento dos juros, a demanda por crédito se retrai, visto que a capacidade de honrar compromissos de hipoteca por parte dos pretensos mutuários diminui. Assim, esse resultado mostra que um aumento da taxa de juros tem forte impacto sobre o mercado imobiliário via mercado de crédito.

A discussão seguinte representa os efeitos do aumento nos preços das habitações na taxa de juros, consumo, inflação e PIB, porém nesse cenário não serão impostas restrições nas respostas estruturais das demais variáveis, sendo observadas as respostas da taxa de juros, consumo, inflação e PIB ao choque. Quanto à natureza desse choque, destaca-se que pode ser proveniente de fatores como aumento da imigração, crescimento excessivo da população (baby boom), ${ }^{5}$ sentimento de mercado (bolha de ativos), entre outros.

$4 \quad$ Mendonça, Medrano e Sachsida (2011) argumentam que o uso de variáveis proxies para o estudo se deu pelo fato de não existirem dados específicos para o setor imobiliário no período de análise. Esse fato ocorreu na Espanha na década de 1970. 
Gráfico 4 - Efeito do choque nos preços das habitações na taxa de juros, inflação e PIB
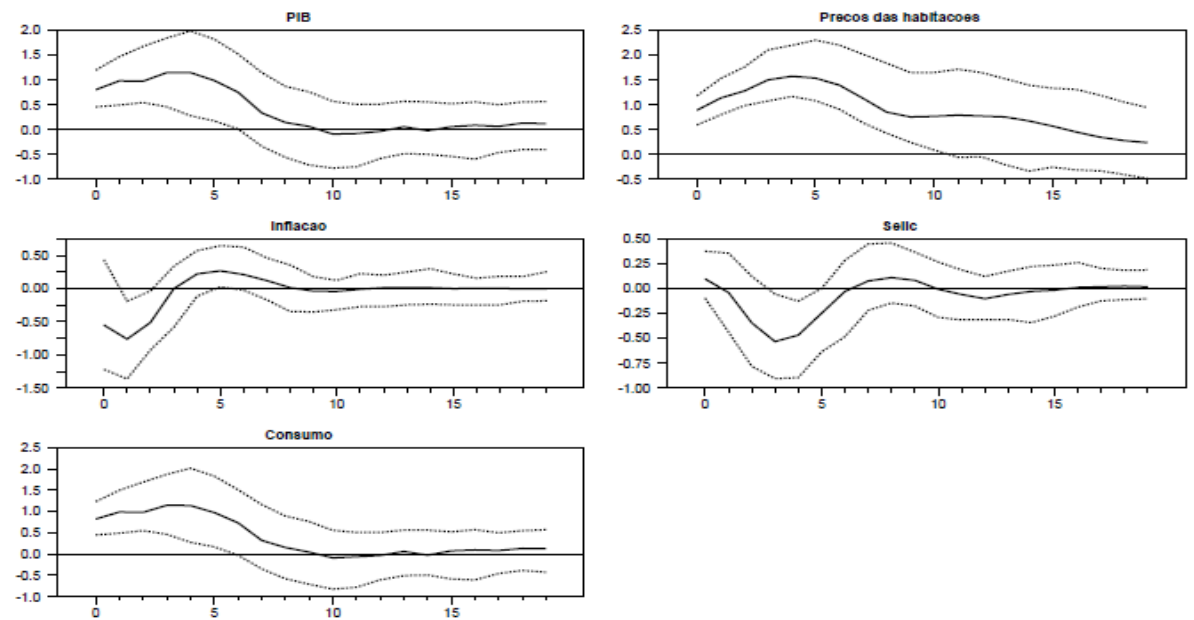

Fonte: Elaboração própria.

Nota: As linhas pontilhadas representam as bandas de probabilidade entre 0.16 e 0.84 , com horizonte de tempo de 20 trimestres e restrição de sinal pura para três trimestres, sendo eliminadas subsequentemente.

Ao se analisar os efeitos do aumento de $1 \%$ nos preços das habitações sobre o consumo, é possível perceber que houve uma expansão inicial do consumo de 1\% e o efeito positivo perdurou durante nove trimestres, em decorrência desse choque. Uma das possíveis explicações para esse comportamento é dada por Browning, Gørtz e Petersen (2013), que sumarizam uma série de estudos, representados por Muellbauer e Murphy (1990), Skinner (1996), Case, Quigley e Shiller (2005), Campbell e Cocco (2007) e Carroll, Otsuka e Slacalek (2011), que encontram resultados que dão suporte aos encontrados nesta pesquisa.

Segundo Browning, Mette e Søren (2013), o mecanismo de transmissão dos preços das habitações para o consumo se dá pelo fato de que mudanças nos preços das casas afetam a riqueza das famílias. De acordo com a hipótese do ciclo de vida, famílias ajustam seu plano de vida em relação ao consumo, à oferta de trabalho e a novas informações sobre a riqueza adquirida ao longo da vida. Assim, as mudanças inesperadas no valor de ativos, decorrentes de alterações dos preços da habitação, podem estimular o consumo das famílias através do efeito riqueza e a demanda agregada, tornando-se um importante mecanismo de transmissão da política monetária.

Quanto aos efeitos sobre a inflação, percebe-se que o aumento nos preços das habitações afetou negativamente a inflação nos três primeiros trimestres, com queda contemporânea 0,5\%; logo após, o nível geral de preços da economia vol- 
tou a subir, ficando acima do patamar inicial. Esse é um resultado curioso, ${ }^{6}$ pois ao se analisar a literatura que trata esses efeitos, grande parte encontra uma relação positiva entre o aumento nos preços das habitações e a inflação, tal como encontram Besarria, Paes e Silva (2016).

A explicação para o resultado encontrado neste artigo passa pela análise entre os preços dos imóveis e o PIB. Como pode ser visto, a expansão nos preços dos imóveis trouxe efeitos positivos para a economia agregada. A explicação para essa relação positiva entre o setor de imóveis e a economia agregada se dá pelo fato de a cadeia produtiva da construção civil representar, aproximadamente, $10 \%$ do PIB da economia brasileira e concentrar uma parcela expressiva de mão de obra, seja qualificada ou não. ${ }^{7}$ Assim, a ampliação da atividade econômica se traduz em aumento na renda e consumo. Quanto à expansão do consumo, o aumento nos preços dos imóveis pode promover uma realocação desse componente, fazendo com que os indivíduos passem a consumir mais bens duráveis e menos bens não duráveis. Esse fato é corroborado na análise da composição da cesta de consumo familiar brasileira, presente no Boletim Regional do Banco Central do Brasil (BANCO CENTRAL DO BRASIL, 2013), de outubro 2013, no qual são apresentadas evidências que indicam que a composição da cesta de consumo familiar brasileira, em âmbito nacional e regional, varia de acordo com a renda disponível familiar per capita. Além disso, a correlação se mostra negativa entre renda e consumo de bens não duráveis e positiva entre renda e gastos com bens duráveis e serviços.

Associando essa característica do perfil de consumo dos brasileiros com o fato de os bens não duráveis representarem 23,61\% do indicador de inflação tratado neste artigo, tem-se uma possível explicação para essa relação negativa, no primeiro momento, entre o aumento nos preços dos imóveis e a inflação.

Além disso, por ser um ativo de baixa elasticidade, o aumento inicial dos preços pode estar refletindo o aumento nos preços das habitações já existentes, em outras palavras, o estoque de habitações. À medida que vão sendo construídas novas habitações, passa a ser demandada uma quantidade maior de fatores de produção, tais como cimento, ferro e mão de obra. Esses subsetores passam a absorver os efeitos do aumento inicial na demanda por habitações e começam a reajustar os preços, aumentando os indicadores de inflação para níveis acima do valor inicial.

Como já descrito anteriormente, esse efeito sobre a inflação fez com que a taxa de juros acompanhasse o comportamento descrito por esse indicador e respondesse inicialmente de forma negativa ao aumento nos preços das habitações, aumentando a partir do terceiro trimestre. Com isso, a conclusão que fica deste

$6 \quad$ Esse caso também pode ser considerado um puzzle de inflação.

7 De acordo com dados do Ministério do Trabalho, em 2012, o setor da construção civil absorveu 7,3\% da mão de obra formal empregada na economia brasileira, sendo o quarto colocado como ramo de atividade que mais emprega no país. 
ensaio é que a taxa de juros responde aos efeitos indiretos do aumento nos preços das habitações, principalmente, ao comportamento da inflação.

\subsection{Decomposição da Variância}

No intuito de avaliar a importância relativa de cada variável na determinação da taxa de juros e dos preços das habitações, foi realizada a decomposição da variância do erro de previsão. A Tabela 4 apresenta a decomposição da variância da taxa de juros.

Tabela 4 - Decomposição da variância da taxa de juros

\begin{tabular}{c|c|c|c|c|c|c}
\hline Período & $\begin{array}{c}\text { Desvio } \\
\text { padrão }\end{array}$ & PIB & Inflação & Consumo & $\begin{array}{c}\text { Preço da } \\
\text { habitação }\end{array}$ & $\begin{array}{c}\text { Taxa de } \\
\text { juros }\end{array}$ \\
\hline $\mathbf{1}$ & 0.73 & 1.48 & 14.01 & 1.34 & 21.81 & 61.34 \\
\hline $\mathbf{5}$ & 1.65 & 2.70 & 15.26 & 8.60 & 25.07 & 48.35 \\
\hline $\mathbf{1 0}$ & 1.97 & 2.55 & 24.83 & 7.78 & 23.18 & 41.63 \\
\hline $\mathbf{1 5}$ & 2.07 & 2.52 & 27.36 & 7.55 & 21.08 & 41.47 \\
\hline $\mathbf{2 0}$ & 2.10 & 3.24 & 27.41 & 7.65 & 20.92 & 40.75 \\
\hline
\end{tabular}

Fonte: Elaboração própria.

Conforme se pode observar, grande parte da variabilidade da taxa de juros é devido à própria variável nos primeiros períodos, embora, em um horizonte temporal mais longo, essa proporção se reduza. Esse comportamento sugere a preferência do Banco Central pela manutenção de uma trajetória suavizada para a taxa de juros, evitando-se, assim, grande variabilidade da variável em questão.

A inflação e os preços das habitações correspondem conjuntamente por 48.33\% da variabilidade dos juros após 20 períodos, evidenciando a importância de ambas na determinação do instrumento de política monetária. Esse resultado está de acordo com o esperado, uma vez que os movimentos na taxa de juros são realizados objetivando manter o crescimento do nível de preços dentro da meta inflacionária estabelecida pelo Comitê de Política Monetária (Copom), enquanto os preços das residências influenciam diretamente a inflação futura, explicando a proporção dessas variáveis sobre a determinação da taxa de juros.

Em menor proporção, o consumo das famílias e o PIB são responsáveis por $7.65 \%$ e 3.24\%, respectivamente, da variância dos juros após 20 períodos, demonstrando a importância da demanda na determinação da política monetária. A Tabela 5 apresenta a decomposição da variância dos preços das habitações. 
Tabela 5 - Decomposição da variância da série de preços das habitações

\begin{tabular}{c|c|c|c|c|c|c}
\hline Passo & $\begin{array}{c}\text { Desvio } \\
\text { padrão }\end{array}$ & PIB & Inflação & Consumo & $\begin{array}{c}\text { Preço da } \\
\text { habitação }\end{array}$ & $\begin{array}{c}\text { Taxa de } \\
\text { juros }\end{array}$ \\
\hline $\mathbf{1}$ & 0.96 & 88.66 & 0.80 & 0.05 & 8.44 & 2.03 \\
\hline $\mathbf{5}$ & 2.93 & 61.63 & 2.63 & 3.50 & 30.55 & 1.66 \\
\hline $\mathbf{1 0}$ & 3.54 & 60.70 & 2.31 & 2.75 & 27.03 & 7.19 \\
\hline $\mathbf{1 5}$ & 3.81 & 61.03 & 5.31 & 2.46 & 23.94 & 7.24 \\
\hline $\mathbf{2 0}$ & 3.90 & 59.90 & 5.89 & 2.43 & 24.22 & 7.54 \\
\hline
\end{tabular}

Fonte: Elaboração própria.

O PIB se mostrou o principal responsável pela variabilidade nos preços habitacionais, com $88.66 \%$, no primeiro período, e $59.90 \%$ após 20 períodos. Esse resultado evidencia a importância da renda agregada sobre os preços das moradias. De fato, o crescimento da renda agregada expande a demanda por residências, afetando diretamente os preços do ativo. Na sequência, a própria variável é responsável por $24.22 \%$, enquanto a taxa de juros por $7.54 \%$ da variância dos preços dos imóveis; este último resultado sugere que a política monetária é capaz de influenciar os preços habitacionais. Por fim, a inflação e o consumo das famílias são responsáveis por $5.89 \%$ e $2.43 \%$ da variabilidade dos preços habitacionais.

\section{Análise de Robustez}

A análise de robustez do exercício do VAR estrutural foi realizada com o propósito de se verificar se os resultados apresentados anteriormente são mantidos quando é alterada a especificação do modelo. O primeiro estágio alterou as restrições impostas nas respostas estruturais para dois trimestres. Em outra análise, as variáveis PIB e Selic foram substituídas pelo PIB da construção civil e pela TJLP. Por fim, foi adotado como especificação alternativa para o SVAR o método de estimação com restrições de curto e longo proposto por Bjørnland e Leitemo (2009) e Bjørnland e Jacobsen (2013). Esses exercícios estão presentes nos Apêndices C, D e E.

Os resultados obtidos mostraram que nenhuma dessas alternativas apresentou alterações na relação entre os preços das habitações e a taxa de juros encontrados no exercício anterior. Esses resultados sugerem que são válidos os efeitos obtidos para o choque nos preços das habitações e o choque monetário, por meio das restrições de sinal propostas por Uhlig (2005). 


\section{Considerações Finais}

Neste artigo foi apresentada uma discussão que trata da interdependência entre os preços das habitações e a política monetária brasileira. A partir dos exercícios propostos nesta pesquisa, foi possível verificar que o choque monetário contracionista trouxe efeitos negativos sobre a inflação, o consumo e o produto real da economia por aproximadamente sete trimestres.

Em relação aos efeitos desse choque nos preços das habitações, foi verificado que o aumento na taxa de juros trouxe efeitos negativos e persistentes nos preços desse ativo. A explicação adotada para o mecanismo de transmissão desse choque foi a mesma proposta por Mendonça e Sachsida (2012), que mostram que a difusão desse choque para os preços habitacionais se dá pelo fato de grande parte das transações realizadas no mercado habitacional brasileiro ser de longa duração e indexada à taxa de juros de longo prazo.

Quanto aos efeitos do aumento nos preços das habitações na taxa de juros, consumo, inflação e PIB, destaca-se que foram encontrados resultados que se aproximam dos achados pela literatura nacional e internacional. O primeiro efeito observado foi o aumento do consumo durante nove trimestres. Como documentado na literatura, esse aumento nos preços das habitações estimula o consumo das famílias através do efeito riqueza e a demanda agregada, fato também encontrado neste estudo.

Por outro lado, verificou-se que a taxa de juros reagiu aos efeitos indiretos causados pelo aumento dos preços das habitações nos indicadores de inflação. Como a inflação reagiu inicialmente de forma negativa e voltou a subir após o terceiro trimestre, esse efeito fez com que a taxa de juros acompanhasse o comportamento descrito por esse indicador e respondesse inicialmente de forma negativa ao aumento nos preços das habitações, aumentando a partir do terceiro trimestre.

Com isso, a conclusão sobre a análise da interdependência entre a taxa de juros e os preços das habitações é: a) o aumento na taxa de juros afetou de forma negativa os preços das habitações por meio do canal do custo do financiamento habitacional; b) a taxa de juros respondeu aos efeitos indiretos do aumento nos preços das habitações, principalmente, ao comportamento da inflação.

\section{Referências}

AKITOBY, B.; STRATMANN, T. Fiscal policy and financial markets. The Economic Journal, v. 118, n. 533, p. 1971-1985, 2008.

ARDAGNA, S. Financial markets' behavior around episodes of large changes in the fiscal stance. European Economic Review, v. 53, n. 1, p. 37-55, 2009. 
BANCO CENTRAL DO BRASIL. Análise da composição da cesta de consumo familiar. Boletim Regional do Banco Central do Brasil, Brasília, v. 7, n. 4, p. 96-104, out. 2013. Disponível em: <http://www.bcb.gov.br/pec/boletimregional/port/2013/10/br201310P.pdf>. Acesso em: 19 fev. 2016.

BERNANKE, B.; GERTLER, M. Monetary policy and asset volatility. Economic Review, v. 84, n. 4, p. 17-51, 1999.

. Should central banks respond to movements in asset prices? The American Economic Review, v. 91, n. 2, p. 253-257, 2001.

BESARRIA, C. N.; PAES, N. L.; SILVA, M. E. A. Como o Banco Central tem reagido aos choques (bolhas) nos preços das habitações brasileiras? Uma análise por meio do modelo dinâmico estocástico de equilíbrio geral (DSGE). Nova Economia, Belo Horizonte, v. 26, n. 2, p. 553-583, 2016.

BJØRNLAND, H. C.; JACOBSEN, D. H. House prices and stock prices: different roles in the U.S. monetary transmission mechanism. Oslo, 2012. (CAMP Working Paper Series n. 1/2012). Disponível em: <https://brage.bibsys.no/xmlui/bitstream/handle/11250/95371/ CAMP_wp_01-2012.pdf?sequence=1EisAllowed=y > . Acesso em: 2 dez. 2014.

. House prices and stock prices: different roles in the US monetary transmission mechanism. The Scandinavian Journal of Economics, v. 115, n. 4, p. 1084-1106, 2013.

; LEITEMO, K. Identifying the interdependence between US monetary policy and the stock market. Journal of Monetary Economics, v. 56, n. 2, p. 275-282, 2009.

BORIO, C.; LOWE, P. Asset prices, financial and monetary stability: exploring the nexus. Basel, Switzerland, 2002. (BIS Working Papers, n. 114, July 2002).

; ZHU, H. Capital regulation, risk-taking and monetary policy: a missing link in the transmission mechanism? Journal of Financial Stability, v. 8, n. 4, p. 236-251, 2012.

BRASIL. Ministério do Trabalho e Emprego. Relação Anual de Informações Sociais ação Anual de Informações Sociais - RAIS. Disponível em: <http://dados.gov.br/dataset/relacao-anualde-informacoes-sociais-rais@2012-01-26T10\%3A57\%3A20.790159>. Acesso em: 20 fev. 2016.

BROWNING, M.; GØRTZ, M.; LETH PETERSEN, S. Housing wealth and consumption: a micro panel study. The Economic Journal, v. 123, n. 568, p. 401-428, 2013.

; METTE, G.; SØREN L. P. Housing wealth and consumption: a micro panel study. The Economic Journal, v. 123, n. 568, p. 401-428, 2013.

CAMPBELL, J.; COCCO, J. How do house prices affect consumption? Evidence from micro data. Journal of Monetary Economics, v. 54, n. 3, p. 591-621, 2007.

CARROLL, C.; OTSUKA, M.; SLACALEK, J. How large are housing and financial wealth effects? A new approach. Journal of Money, Credit, and Banking, v. 43, n. 1, p. 55-79, 2011.

CASE, K. E.; QUIGLEY, J. M.; SHILLER, R. J. Comparing wealth effects: the stock market versus the housing market. Advances in Macroeconomics, v. 5, n. 1, p. 1-32, 2005. 
CHRISTIANO, L. J.; EICHENBAUM, M.; EVANS, C. L. Monetary policy shocks: what have we learned and to what end? Cambridge, MA, US, 1998. (NBER Working Paper, n. 6400).

. Nominal rigidities and the dynamic effects of a shock to monetary policy. Journal of Political Economy, Chicago, IL, US, v. 113, n. 1, p. 1-45, Feb. 2005.

FAUST, J. The robustness of identified VAR conclusions about money. Carnegie-Rochester Conference Series in Public Policy, v. 49, p. 207-244, Dec. 1998.

FILARDO, A. J. Monetary policy and asset prices. Economic Review, v. 85, n. 3, p. 11-37, 2000 .

FURLANETTO, F. Does monetary policy react to asset prices? Some international evidence. International Journal of Central Banking, v. 7, n. 3, p. 91-111, Sept. 2011.

GIULIODORI, M. Monetary policy shocks and the role of house prices across European countries. Amsterdam, Netherlands, 2004. (DNB Working Paper, n. 15, Nov. 2004).

GOODHART, C.; HOFMANN, B. House prices, money, credit and the macroeconomy. Frankfurt am Main, Germany, 2008. (ECB Working Paper Series, n. 888, Apr. 2008).

JAPPELLI, T.; PISTAFERRI, L. The consumption response to income changes. Annual Review of Economics, v. 2, n. 1, p. 479-506, 2010.

KUTTNER, K. Monetary policy and asset price volatility: should we refill the Bernanke-Gertler prescription? Williams College, Department of Economics, Jun. 2011. (Working Papers 2011-04).

LÜTKEPOHL, H. New introduction to multiple time series analysis. [S. 1.]: Springer Science $\mathcal{E}$ Business Media, 2005.

MENDONÇA, M. J. O crédito imobiliário no Brasil e sua relação com a política monetária. Revista Brasileira de Economia, Rio de Janeiro, v. 67, n. 4, p. 457-495, 2013.

; MEDRANO, L. A.; SACHSIDA, A. Avaliando o efeito de um choque de política monetária sobre o mercado imobiliário. Brasília, 2011. (Texto para discussão n. 1631, jul. 2011).

; SACHSIDA, A. Existe bolha no mercado imobiliário brasileiro? Brasília, 2012. (Texto para discussão n. 1762, ago. 2012).

MUELBAUER, J.; MURPHY, A. Is the UK balance of payments sustainable? Economic Policy, v. 11, n. 3, p. 345-383, 1990.

PEERSMAN, G.; SMETS, F. The monetary transmission mechanism in the euro area: more evidence from VAR analysis. Frankfurt am Main, Germany, 2001. (ECB Working Paper Series, n. 91, Dec. 2001).

SILVA, M. E.; BESARRIA, C. N.; CARVALHO, D. B. Efeitos dos choques fiscais e monetários sobre o mercado imobiliário brasileiro. In: ENCONTRO BRASILEIRO DE ECONOMETRIA, 36., 2014, Natal. Anais... Rio de Janeiro: Sociedade Brasileira de Econometria, 2014. p. 1-22. 
SIMS, C. A. Comparison of interwar and postwar business cycles: monetarism reconsidered. American Economic Review, v. 70, n. 2, p. 250-257, 1980.

SKINNER, J. Is housing wealth a side show? In: WISE, D. (Ed.). Advances in the economics of aging. Chicago, IL: University of Chigaco Press, 1996. p. 241-68.

SVENSSON, L. E. O. Inflation forecast targeting: implementing and monitoring inflation targets. European Economic Review, v. 41, n. 6, p. 1111-1146, June 1997.

TAN, Z.; CHEN, M. House prices as indicators of monetary policy: evidence from China. Stanford Center for International Development. Stanford, CA, US, 2013. (Working Paper n. 488, Dec. 2013).

UHLIG, H. The robustness of identified VAR conclusions about money: a comment. CarnegieRochester Series in Public Economics, v. 49, p. 245-263, Dec. 1998.

. What are the effects of monetary policy on output? Results from an agnostic identification procedure. Journal of Monetary Economics, v. 52, n. 2, p. 381-419, Mar. 2005.

VICKERS, J. Monetary policy and asset prices. Bank of England Quarterly Bulletin, London, v. 39, p. 428-435, 1999.

\section{Apêndice A - Testes de Cointegração}

Tabela 6 - Análise de cointegração

\begin{tabular}{c|ccccccc}
\hline & \multicolumn{3}{|c}{ Johansen } & \multicolumn{2}{c}{ Engle-Granger } & Phillips-Perron \\
\hline & Eigenvalue & Traço & Traço (95\%) & & & & \\
\hline 0 & 0.74 & 66.62 & 69.61 & $\begin{array}{c}\text { Estatística } \\
\text { do teste } \\
\text { Valor }\end{array}$ & -2.05 & $\begin{array}{c}\text { Estatística } \\
\text { do teste }\end{array}$ & -1.87 \\
1 & 0.42 & 27.11 & 47.71 & $\begin{array}{c}\text { Valor } \\
\text { crítico }\end{array}$ & -4.71 & crítico & -4.68 \\
\hline
\end{tabular}

Fonte: Elaboração própria.

\section{Apêndice B - Teste de Chow para os modelos SVAR}

Suponha-se que houve uma alteração nos parâmetros do processo VAR (p) no período após , tal como propõe Lütkepohl (2005). Dada uma amostra $\mathrm{y}_{1}, \ldots, \mathrm{y}_{\mathrm{T}}, \mathrm{O}$ modelo pode ser configurado da seguinte forma para fins de estimação:

$$
\left[\mathrm{Y}_{(1)}: \mathrm{Y}_{(2)}\right]=\left[\mathrm{B}_{1}: \mathrm{B}_{2}\right] \mathrm{Z}+\left[\mathrm{U}_{(1)}: \mathrm{U}_{(2)}\right]=\mathrm{BZ}+\mathrm{U}
$$

em que $\left.\mathrm{Y}_{(1)}=\left[\mathrm{y}_{1}, \ldots, \mathrm{y}_{\mathrm{T}}\right], \mathrm{Y}_{(2)}=\left[\mathrm{y}_{\mathrm{T} 1}+1\right), \ldots, \mathrm{y}_{\mathrm{T}}\right]$, sendo $\mathrm{U}$ particionado em conformidade com os valores de $\mathrm{Y} ; \mathrm{B}_{1}=\left[\mathrm{v}_{1}, \mathrm{~A}_{11}, \ldots, \mathrm{A}_{\mathrm{p} 1}\right]$, e $\mathrm{B}_{2}=\left[\mathrm{v}_{2}, \mathrm{~A}_{12}, \ldots, \mathrm{A}_{\mathrm{p} 2}\right]$ são os $[\mathrm{K}(\mathrm{pK}+1)]$ 
parâmetros associados com o primeiro $\left(\mathrm{t}=1, \ldots, \mathrm{T}_{1}\right)$ e o último $\left(\mathrm{t}=\mathrm{T}_{1}+1, \ldots, \mathrm{T}\right)$ subperíodos, respectivamente; $B=\left[B_{1}: B_{2}\right]$ é $[K 2(K p+1)]$ dimensional e $Z=\left|Z_{(1)} 00 \quad Z_{(2)}\right|$.

Nesse ponto, $Z_{(1)}=\left[Z_{0}, \ldots, Z_{T 1}-1\right]$ e $Z_{(2)}=\left[Z_{T 1}, \ldots, Z_{T-1}\right] \operatorname{com} Z_{t}^{\prime}=\left(1, y_{t}^{\prime}, \ldots, y_{t-p+1}^{\prime}\right)$. Tomando-se como base a discussão apresentada, um teste para se verificar a constância ou estabilidade dos parâmetros do modelo VAR é dado pela seguinte estatística de teste:

$$
\left[\mathrm{H}_{0}: \mathrm{B}_{1}=\mathrm{B}_{2} \mathrm{H}_{1}: \mathrm{B}_{1} \neq \mathrm{B}_{2}\right.
$$

A hipótese nula do teste garante a constância dos parâmetros entre períodos distintos. Neste artigo, o teste foi aplicado para os períodos entre de 2008 e 2011 , caracterizados como momentos de instabilidade econômica. A definição desses períodos foi dada com base na crise subprime, no caso do primeiro momento, e pela transição política ocorrida no ano de 2011 (mudança de presidente da República). Os resultados do teste de Chow são apresentados na Tabela 7.

Tabela 7 - Teste de Chow para quebra estrutural dos parâmetros do modelo VAR

\begin{tabular}{c|cc}
\hline Momentos de quebra estrutural & $\chi_{(55)}^{2}$ & Probabilidade \\
\hline $2008: 04$ & 35.54 & 0.98 \\
$2011: 04$ & 8.36 & 0.99 \\
\hline
\end{tabular}

Fonte: Elaboração própria.

Como pode ser visto na Tabela 7, os resultados corroboram a hipótese de estabilidade dos parâmetros do modelo VAR em diferentes amostras. Uma crítica potencial a esse tipo de procedimento é o fato de o teste de Chow ser baseado na hipótese de conhecimento prévio do momento da quebra estrutural. 


\section{Apêndice $C$ - Alteração no período de restrição $(K=2)$}

Gráfico 5 - Efeito do choque contracionista de política monetária no PIB, consumo, inflação e preços das habitações
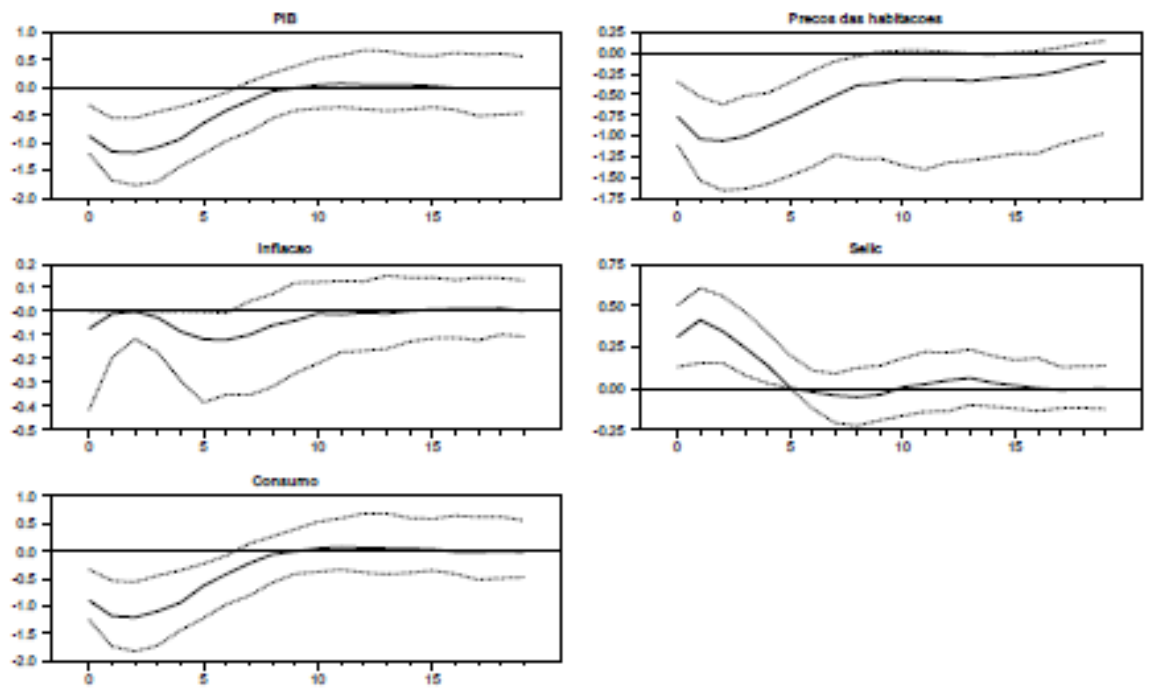

Fonte: Elaboração própria

Gráfico 6 - Efeito do choque nos preços das habitações na taxa de juros, PIB, consumo, inflação e preços das habitações
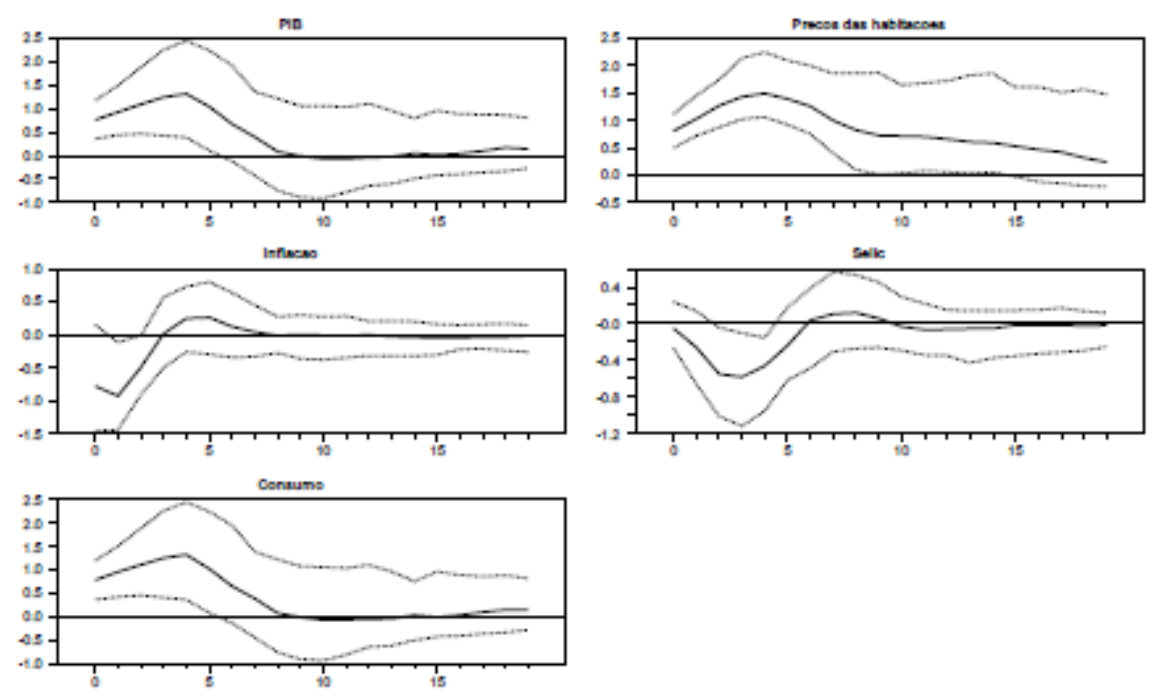

Fonte: Elaboração própria 


\section{Apêndice D - Alteração da variável Selic pela TJLP e o PIB pelo PIB da}

construção civil

Gráfico 7 - Efeito do choque contracionista de política monetária no PIB, consumo, inflação e preços das habitações
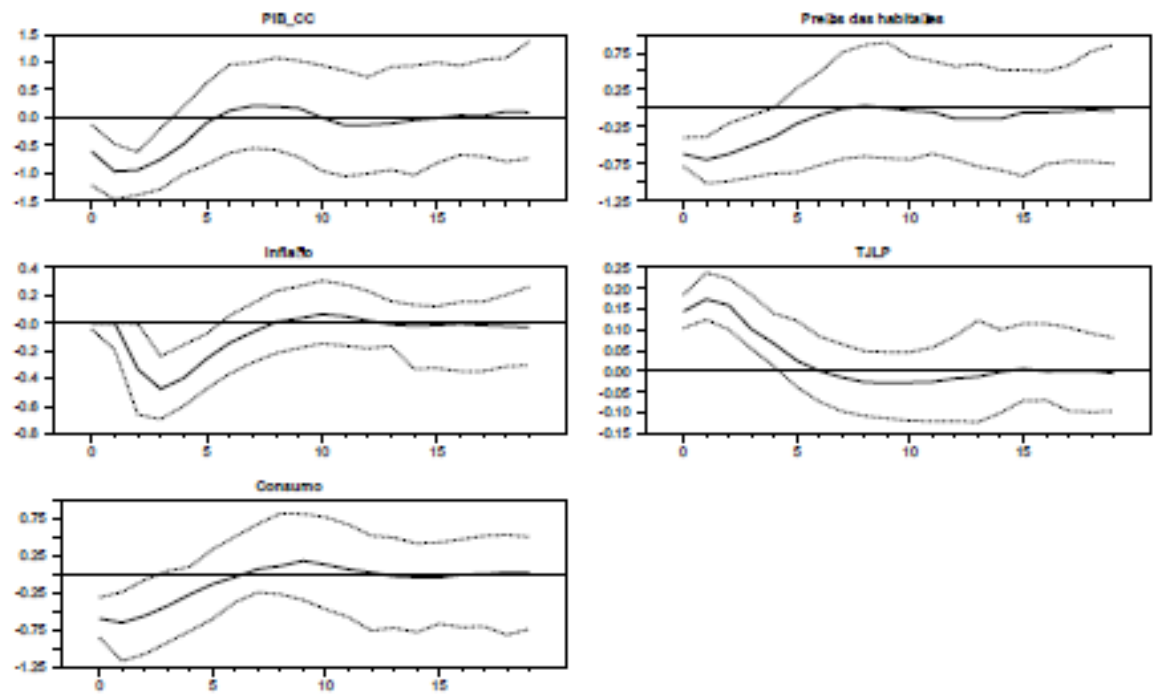

Responses to Politica Monetaria

Fonte: Elaboração própria 
Gráfico 8 - Efeito do choque nos preços das habitações na taxa de juros, PIB, consumo, inflação e preços das habitações
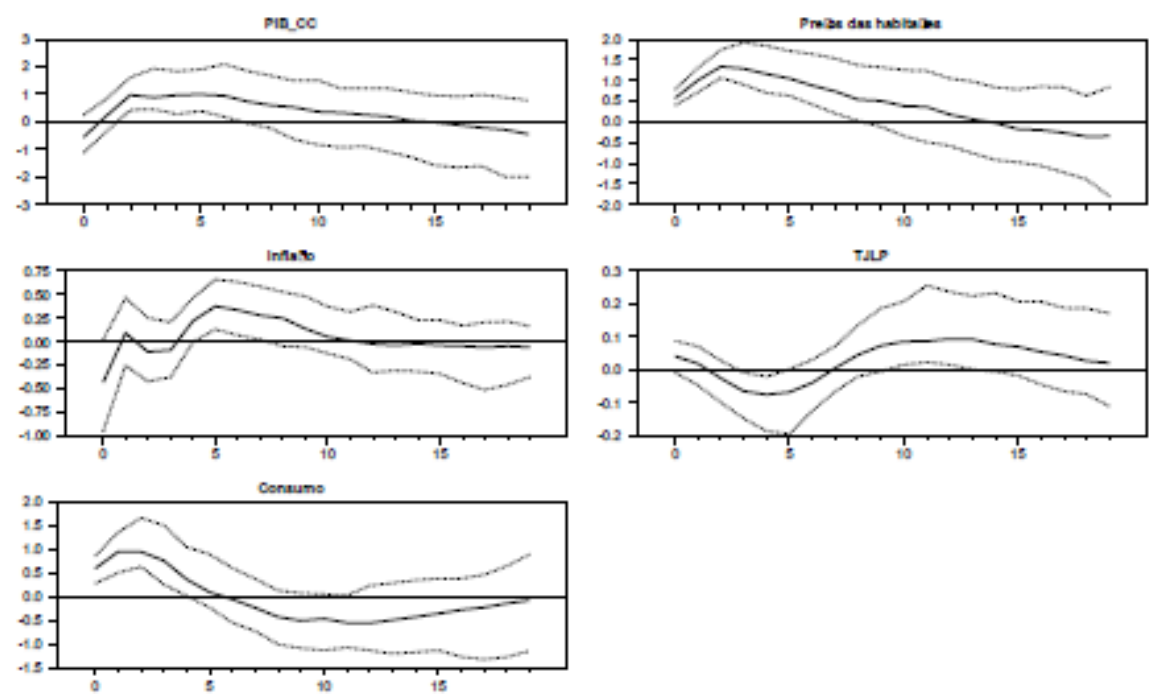

Responses to Precos das habitacoes

Fonte: Elaboração própria

\section{Apêndice E - Método proposto por Biørnland e Leitemo (2009) e Biørnland e Jacobsen (2013)}

$\mathrm{O}$ vetor $Z_{\mathrm{t}}$ é modelado como um processo autorregressivo que, quando invertido, pode ser escrito em termos de sua média móvel:

$$
\mathrm{Z}_{\mathrm{t}}=\mathrm{B}(\mathrm{L}) \mathrm{v}_{\mathrm{t}}
$$

em que $v_{t}$ é um vetor na forma reduzida, assumido como idêntico e independentemente distribuído com uma matriz de covariância semidefinida positiva e $\mathrm{B}(\mathrm{L})$ é uma matriz (5x5) convergente de polinômios no operador de lags L. Seguindo a literatura, as inovações $\mathrm{v}_{t}$ são assumidas como combinações lineares dos distúrbios estruturais ortogonais $\left(\varepsilon_{\mathrm{t}}\right)$, isto é, $\mathrm{v}_{\mathrm{t}}=\mathrm{S} \varepsilon_{\mathrm{t}}$.

O VAR pode ser escrito em termos de choques estruturais como:

$$
\mathrm{Z}_{\mathrm{t}}=\mathrm{C}(\mathrm{L}) \varepsilon_{\mathrm{t}}
$$

em que $\mathrm{B}(\mathrm{L}) \mathrm{S}=\mathrm{C}(\mathrm{L})$. Se $\mathrm{S}$ for identificado, pode-se derivar a representação em (C2), assim como $\mathrm{B}(\mathrm{L})$ é calculado a partir da estimativa da forma reduzida $Z_{\mathrm{t}}$ de 
para se identificar os elementos $\mathrm{S}$, em que $\varepsilon_{\mathrm{t}}$ são normalizados para que todos tenham variância unitária. Dado que o VAR possui cinco variáveis, então é possível identificar cinco choques estruturais.

Os dois choques que são de interesse principal nesta pesquisa são os choques de política monetária $\left(\varepsilon_{\mathrm{t}}^{\mathrm{MP}}\right)$, e os choques nos preços das habitações $\left(\varepsilon_{\mathrm{t}}^{\mathrm{PH}}\right)$. Ordenando-se o vetor de choques estruturais, tem-se que:

$$
\varepsilon_{\mathrm{t}}=\left[\varepsilon_{\mathrm{t}}^{\mathrm{y}}, \varepsilon_{\mathrm{t}}^{\pi}, \varepsilon_{\mathrm{t}}^{\mathrm{C}}, \varepsilon_{\mathrm{t}}^{\mathrm{PH}}, \varepsilon_{\mathrm{t}}^{\mathrm{MP}}\right] \text { ' }
$$

Dessa forma, obtém-se a seguinte matriz:

$\left(\Delta \mathrm{y}_{\mathrm{t}} \pi_{\mathrm{t}} \Delta \mathrm{c}_{\mathrm{t}} \Delta \mathrm{ph}_{\mathrm{t}} \mathrm{i}_{\mathrm{t}}\right)=\left(\mathrm{S}_{11} \mathrm{~S}_{21} \mathrm{~S}_{31} \mathrm{~S}_{41} \mathrm{~S}_{51} 0 \mathrm{~S}_{22} \mathrm{~S}_{32} \mathrm{~S}_{42} \mathrm{~S}_{52} 00 \mathrm{~S}_{33} \mathrm{~S}_{43} \mathrm{~S}_{53} 00 \mathrm{~S}_{34} \mathrm{~S}_{44} \mathrm{~S}_{54} 00\right.$
$0 \mathrm{~S}_{45} \mathrm{~S}_{55}\left(\varepsilon_{\mathrm{t}}^{\mathrm{y}} \varepsilon_{\mathrm{t}}^{\pi} \varepsilon_{\mathrm{t}}^{\mathrm{c}} \varepsilon_{\mathrm{t}}^{\mathrm{PH}} \varepsilon_{\mathrm{t}}^{\mathrm{MP}}\right)$

Bjørnland e Leitemo (2009) assumem recursivamente restrições com valores zero sobre a matriz de impacto de choques $S$ para as variáveis macroeconômicas tradicionais, assim como Sims (1980), Christiano, Eichenbaum e Evans (1998, 2005), entre outros. Ou seja, o produto da inflação reage com uma defasagem de choques de política monetária, enquanto que o formulador de políticas monetárias pode responder imediatamente ao choque no produto e inflação, que é consistente com o conjunto teórico de Svensson (1997). Além disso, adota-se ainda um atraso no efeito dos choques nos preços das habitações sobre a inflação e o produto.

A matriz $S$ mostra que a política monetária deve responder contemporaneamente a choques nos preços das habitações (ou seja, $S_{53}$ e $S_{54}$ devem ser diferentes de zero) ou, alternativamente, os preços das habitações devem responder simultaneamente a choques de política monetária (ou seja, $S_{35}$ e $S_{45}$ devem ser diferentes de zero). Os resultados obtidos nessa etapa são descritos nos Gráficos 9 e 10. 
Gráfico 9 - Efeito do choque contracionista de política monetária no PIB, consumo, inflação e preços das habitações
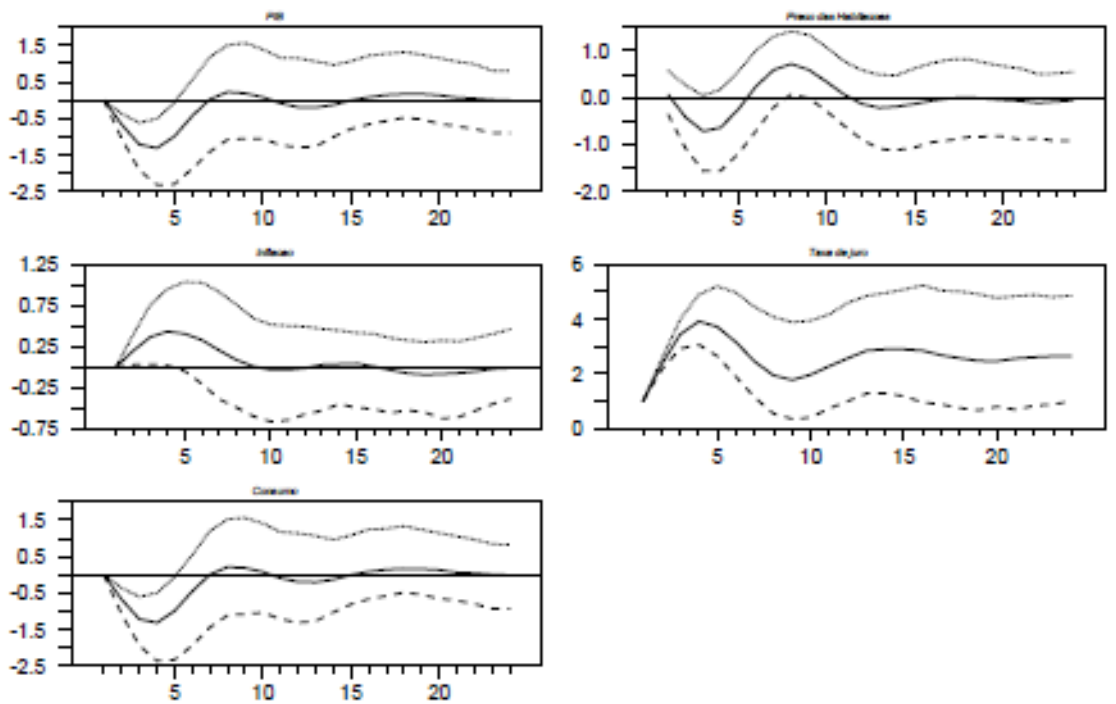

Fonte: Elaboração própria.

Gráfico 10 - Efeito do choque nos preços das habitações na taxa de juros, PIB, consumo, inflação e preços das habitações
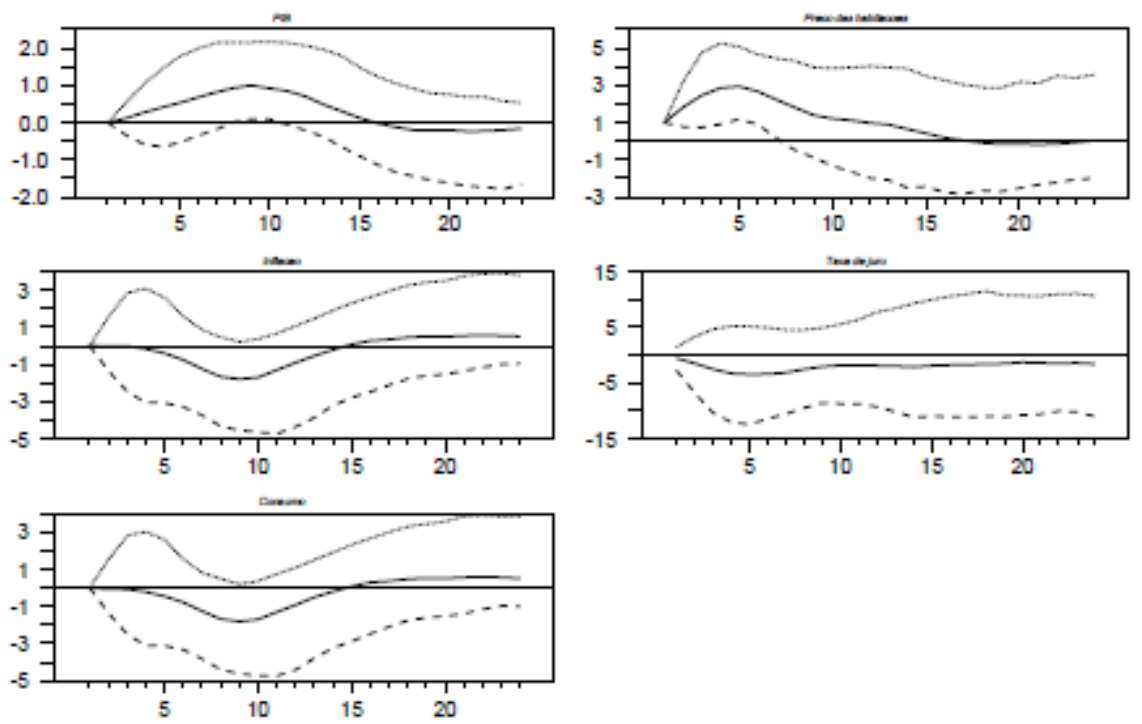

Fonte: Elaboração própria.

Recebido em: 21/03/2016.

Aceito em: 20/02/2017. 